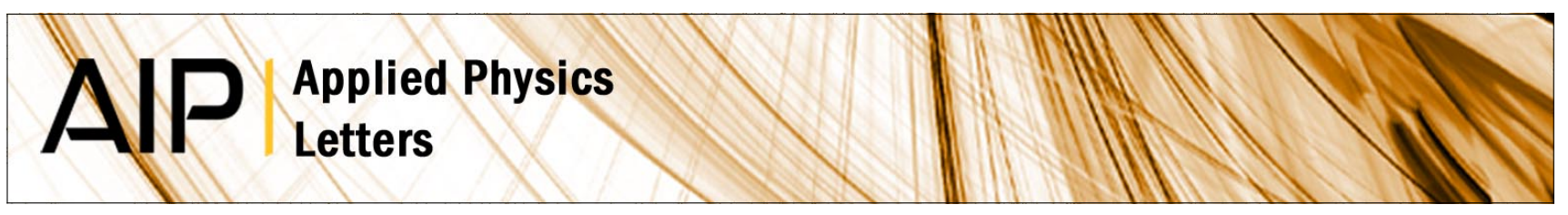

\title{
Pulsed laser deposition of liquid crystals
}

J. Gonzalo, P. E. Dyer, and M. Hird

Citation: Appl. Phys. Lett. 71, 2752 (1997); doi: 10.1063/1.120124

View online: http://dx.doi.org/10.1063/1.120124

View Table of Contents: http://apl.aip.org/resource/1/APPLAB/v71/i19

Published by the American Institute of Physics.

\section{Related Articles}

Charge localization at the interface between La1-xSrxMnO3 and the "infinite layers" cuprate $\mathrm{CaCuO} 2$ J. Appl. Phys. 112, 123901 (2012)

Resonant photoemission study of epitaxial La0.7Sr0.3MnO3 thin film across Curie temperature Appl. Phys. Lett. 101, 242402 (2012)

Physical properties of CdTe:Cu films grown at low temperature by pulsed laser deposition J. Appl. Phys. 112, 113110 (2012)

Combinatorial matrix-assisted pulsed laser evaporation: Single-step synthesis of biopolymer compositional gradient thin film assemblies

Appl. Phys. Lett. 101, 233705 (2012)

Determination of optical and microstructural parameters of ceria films

J. Appl. Phys. 112, 103535 (2012)

\section{Additional information on Appl. Phys. Lett.}

Journal Homepage: http://apl.aip.org/

Journal Information: http://apl.aip.org/about/about_the_journal

Top downloads: http://apl.aip.org/features/most_downloaded

Information for Authors: http://apl.aip.org/authors

\section{ADVERTISEMENT}

\section{AIP Applied Physics Letters}

\section{EXPLORE WHAT'S NEW IN APL}

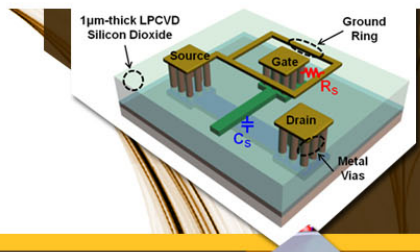

SURFACES AND INTERFACES

Focusing on physical, chemical, biological structural, optical, magnetic and electrical properties of surfaces and interfaces, and more.. 


\section{Pulsed laser deposition of liquid crystals}

J. Gonzalo, ${ }^{\text {a) }}$ P. E. Dyer, and M. Hird

Departments of Physics and Chemistry, University of Hull. Hull, HU6 7RX, United Kingdom.

(Received 14 July 1997; accepted for publication 9 September 1997)

Thin films of 4-cyano-4'-pentylbiphenyl (5CB) liquid crystal have been fabricated by pulsed laser deposition. The suitability of different lasers $\left(\mathrm{ArF}, \mathrm{KrF}\right.$ and $\left.\mathrm{CO}_{2}\right)$ has been investigated over a range of fluence using visible-UV and infrared absorption and optical microscopy to characterise the films. High performance liquid chromatography (HPLC) and matrix assisted laser desorption ionization mass spectroscopy (MALDI-MS) were used to assess the extent of decomposition of the films. The results suggest that the $\mathrm{CO}_{2}$ laser acts as a quasi-steady heat source, while for ArF laser irradiation severe photodecomposition is observed. However, use of the $\mathrm{KrF}$ laser allows the production of excellent quality submicron films, showing properties similar to the 5CB target with only slight photodecomposition. (C) 1997 American Institute of Physics. [S0003-6951(97)00845-0]

The production of liquid crystal (LC) thin films is expected to become important in the development of optoelectronic devices such as optical modulators, frequency convertors, tunable optical filters and flat screen displays among others. ${ }^{1}$ A variety of processing methods for film formation are available based on, for example, capillary action, vacuum evaporation or dispersion of the $\mathrm{LC}$ in a polymeric matrix. Nevertheless, these methods are not always suitable for certain materials or applications, e.g. ultra-thin, uniform films of ferroelectric or discotic LCs; thus, the development of alternative methods for producing these films for advanced technological applications is of considerable interest.

During the past decade pulsed laser deposition (PLD) has developed rapidly and is now one of the most general techniques for the production of thin films of inorganic compounds. ${ }^{2}$ In contrast, except for some polymers, ${ }^{3-5}$ the application of PLD to organic compounds has been less widely investigated. This stems, in part, from the existence of photodisociative processes during the laser target/plume interaction $^{5,6}$ that may alter the chemical properties of the deposited films, although PLD has recently been applied successfully to complex organic compounds such as Pentacene, ${ }^{7}$ Copper-phthalocyanine and 4-dialkylamine-4'-nitrostilbene. ${ }^{8}$

The aim of work reported here was to evaluate the suitability of PLD for the deposition of LC thin films and to investigate the influence of laser fluence and wavelength on the properties of the deposited material. We demonstrate that by suitable choice of the laser parameters, high quality uniform films with thicknesses $<1 \mu \mathrm{m}$ can be formed, albeit with some degree of decomposition accompanying the deposition step.

The LC investigated was 4-cyano-4'-pentylbiphenyl (5CB, BDH, Poole Ltd.) whose molecular structure is shown in the inset of Fig. 1. It has a nematic range of $24.0-35.3{ }^{\circ} \mathrm{C}^{9}$ and a normal boiling point $\geqslant 400{ }^{\circ} \mathrm{C}$. PLD from a $5 \mathrm{CB}$ liquid target held in a $7 \mathrm{~mm}$ diameter horizontally mounted stationary dish, was used to grow films on various substrates (glass, fused silica, $\mathrm{NaCl}$ ) held at room temperature in a vacuum chamber at $1 \times 10^{-5}$ mbar. The laser was focused onto the liquid surface to form a 1-2 $\mathrm{mm}^{2}$ spot and the ejected mate-

${ }^{a)}$ Electronic mail: j.gonzalo@physics.hull.ac.uk rial was collected on substrates placed $30 \mathrm{~mm}$ above the target surface. ArF (193 nm, $\tau=25 \mathrm{~ns}$ pulse width, $\nu=10 \mathrm{~Hz}$ pulse rate), $\mathrm{KrF}(248 \mathrm{~nm}, \tau=25 \mathrm{~ns}, \nu=10 \mathrm{~Hz})$ and $\mathrm{CO}_{2}(10.6 \mu \mathrm{m}, \tau=100 \mathrm{~ns}, \nu=8 \mathrm{~Hz})$ lasers were used as the deposition sources. The effect of fluence was investigated in the range $20-100 \mathrm{~mJ} / \mathrm{cm}^{2}$ for the $\mathrm{ArF}$ and $\mathrm{KrF}$ lasers, and $0.6-3.0 \mathrm{~J} / \mathrm{cm}^{2}$ for the $\mathrm{CO}_{2}$ laser, the lower value in each case corresponding to the threshold below which film formation could not be detected. In no case was a visible plume seen to accompany the interaction. During the deposition, a thermocouple was used to measure the average temperature of the 5CB liquid pool which was found to reach up to $70{ }^{\circ} \mathrm{C}$ in the case of the $\mathrm{CO}_{2}$ (mean power $=160 \mathrm{~mW}$ at $1.4 \mathrm{~J} / \mathrm{cm}^{2}$ ), but remained near room temperature $\left(\sim 20^{\circ} \mathrm{C}\right)$ for the $\mathrm{ArF}$ and the $\mathrm{KrF}$ lasers (mean power $=20 \mathrm{~mW}$ at $100 \mathrm{~mJ} / \mathrm{cm}^{2}$ ).

The optical properties of the deposited films were characterised by visible-UV and infrared (IR) absorption and optical microscopy. High Performance Liquid Chromatography (HPLC) and Matrix Assisted Laser Desorption Ionisation Mass Spectrometry (MALDI-MS, $3 \mathrm{~ns}, \mathrm{~N}_{2}$ laser desorption source) were used to assess the extent of 5CB decomposition in the films. The properties of the laser deposited films were compared with those grown by thermal evaporation at $70{ }^{\circ} \mathrm{C}$ in vacuum and with reference samples obtained by wiping a small amount of $5 \mathrm{CB}$ on the appropriate substrate.

Visible-UV absorption spectra in the range $200-600 \mathrm{~nm}$

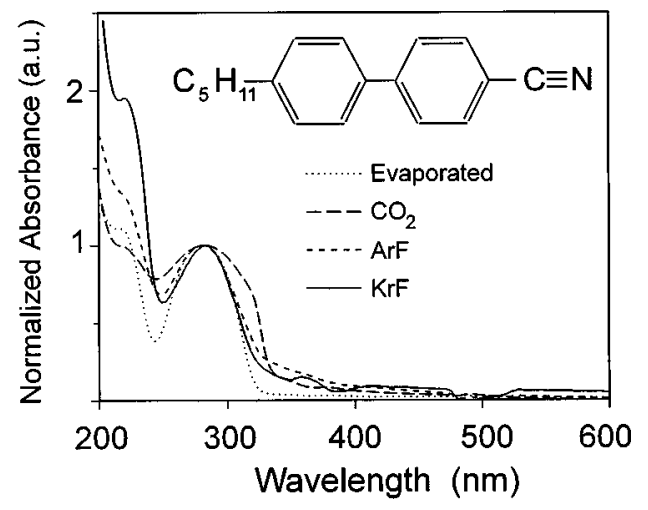

FIG. 1. Normalized absorption spectra of: thermally evaporated film and films deposited with $\mathrm{CO}_{2}$ laser at $1.4 \mathrm{~J} / \mathrm{cm}^{2}$, ArF laser at $30 \mathrm{~mJ} / \mathrm{cm}^{2}$ and $\mathrm{KrF}$ laser at $60 \mathrm{~mJ} / \mathrm{cm}^{2}$. The inset shows chemical structure of $5 \mathrm{CB}$. 

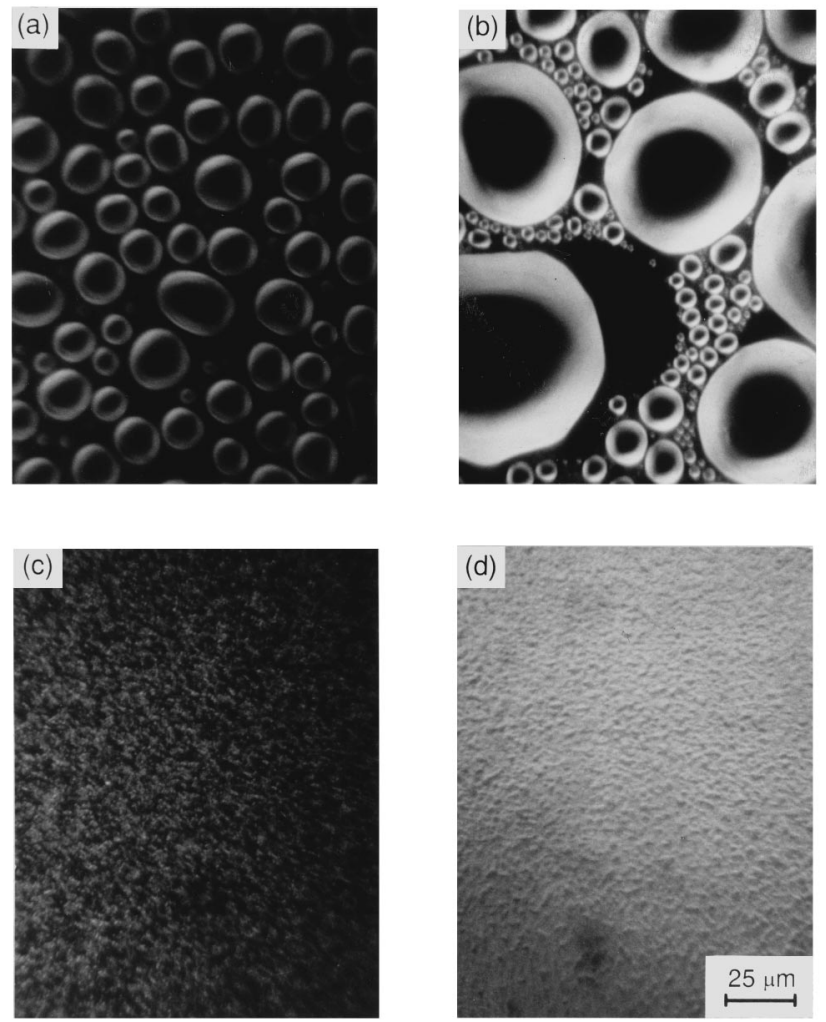

FIG. 2. Optical micrographs $(\times 400$ magnification $)$ of films prepared by (a) $\mathrm{CO}_{2}$ laser at $1.4 \mathrm{~J} / \mathrm{cm}^{2}$, (b) thermal evaporation, (c) ArF laser at $30 \mathrm{~mJ} / \mathrm{cm}^{2}$ and (d) $\mathrm{KrF}$ laser at $100 \mathrm{~mJ} / \mathrm{cm}^{2}$.

(1 $\mathrm{nm}$ resolution) are shown in Fig. 1 for thermally evaporated and $\mathrm{ArF}, \mathrm{KrF}$ and $\mathrm{CO}_{2}$ laser deposited films. As these films have different thicknesses the spectra have been normalised to the absorbance at $280 \mathrm{~nm}$ to ease comparison. The spectra shown in Fig. 1 are broadly similar to that of the 5CB reference sample, with two bands centred at 200 and $280 \mathrm{~nm}$ related to $\pi \rightarrow \pi^{*}$ electronic transitions in the phenyl rings. ${ }^{9}$ This gives qualitative evidence for the phenyl rings remaining basically unaltered in the molecules of the deposited films. The electronic transitions responsible for these absorption bands have been assigned to be polarised parallel (280 $\mathrm{nm})$ and both parallel and perpendicular $(220 \mathrm{~nm})$ to the long axis of the biphenyl group. ${ }^{10}$ Therefore, the difference in the intensity ratio $\left(\mathrm{I}_{220} / \mathrm{I}_{280}\right)$ between films grown with UV lasers $(>1)$ and either with the $\mathrm{CO}_{2}$ laser or by thermal evaporation $(\sim 1)$ suggests a different orientation of the molecules in the films. The origin of this difference is unclear, but could be related to the laser-LC interaction process and a possible difference in the ejection mechanisms between UV and IR lasers.

Optical microscopy of films grown using the three laser wavelengths revealed significantly different morphologies. For the $\mathrm{CO}_{2}$ laser (Fig. 2a) the film consisted of an aggregation of droplets homogeneously distributed on the substrate, the typical droplet diameter being $\sim 15 \mu \mathrm{m}$ at $1.4 \mathrm{~J} / \mathrm{cm}^{2}$. The droplet size decreased with increasing fluence. This morphology is qualitatively similar to that for thermally evaporated films (Fig. 2b) although these showed a much broader range of droplet diameters. In contrast, films formed using the $\mathrm{ArF}$ and $\mathrm{KrF}$ lasers were, in relative terms, extremely

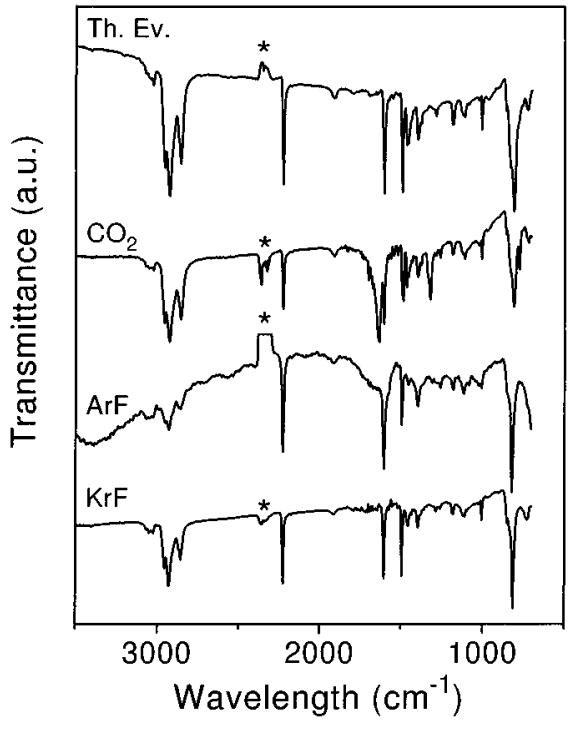

FIG. 3. Infrared spectra of thermally evaporated film and films grown with $\mathrm{CO}_{2}$ laser at $1.4 \mathrm{~J} / \mathrm{cm}^{2}$, ArF laser at $30 \mathrm{~mJ} / \mathrm{cm}^{2}$ and $\mathrm{KrF}$ laser at $100 \mathrm{~mJ} /$ $\mathrm{cm}^{2}$. In order to ease the comparison, the transmittance of the $\mathrm{CO}_{2}$ and the ArF laser deposited films is scaled by a factor of 4 and 6.5 respectively. The feature designed by $(*)$ corresponds to the water vapour absorption band that is incompletely cancelled in the differential measurements.

smooth (Figs. 2c and 2d) and no significant features could be resolved above $1 \mu \mathrm{m}$. Based on their $280 \mathrm{~nm}$ absorption, ${ }^{9}$ the thickness of the $\mathrm{ArF}$ and $\mathrm{KrF}$ laser produced films was estimated to be $0.2-0.4 \mu \mathrm{m}$, corresponding to an average growth rate of $\sim 5 \times 10^{-3} \mathrm{~nm}$ per pulse.

HPLC analysis of reference samples, and the thermally evaporated and $\mathrm{CO}_{2}$ laser grown films, revealed only a single peak corresponding to the $5 \mathrm{CB}$ molecule. It can thus be ascertained that up to at least $3 \mathrm{~J} / \mathrm{cm}^{2}$ the $\mathrm{CO}_{2}$ laser produces no appreciable decomposition. For the ArF laser, HPLC analysis of the films showed extensive fragmentation, four peaks appearing at earlier retention times in the spectrum in addition to a peak for 5CB. These fragment signatures became more pronounced as the fluence was raised, and even at as low as $60 \mathrm{~mJ} / \mathrm{cm}^{2} 5 \mathrm{CB}$ was rendered a minority peak. MALDI-MS spectra of ArF laser deposited films on a Coumarin 120 matrix confirmed the decomposition, many fragment peaks appearing in the mass spectrum (e.g. at 74, 103, 165, $217 \mathrm{Da}$; 5CB molecular weight $=249 \mathrm{Da})$. For $\mathrm{CO}_{2}$ laser deposited films, a peak was observed at $231 \mathrm{Da}$ in addition to the $249 \mathrm{Da}$ peak. The fact that such decomposition could not be observed by HPLC suggests a small fractional decomposition, or that these similar mass components could not be resolved. Finally, the HPLC spectra of the $\mathrm{KrF}$ laser deposited films showed the 5CB peak and a weaker one appearing at an earlier time, and thus probably corresponding to a smaller molecule.

IR spectra were obtained for the thermally evaporated and the laser deposited films (Fig. 3) as well as for the 5CB reference sample on $\mathrm{NaCl}$. All bands, with the exception of a weak feature at $1287 \mathrm{~cm}^{-1}$, could be assigned from tabulated data. ${ }^{11}$ There is a close match between the spectra for thermally evaporated and $\mathrm{CO}_{2}$ laser deposited films (Fig. 3) although for the latter, two new weak bands at 1640 and $1320.8 \mathrm{~cm}^{-1}$ and significant broadening of the $1600 \mathrm{~cm}^{-1}$ 
band are evident. These changes could be related to the partial decomposition of the 5CB molecules suggested by the MALDI-MS experiments. Considering the bond strengths (C-C and C-H dissociation energies are $\sim 3.5$ and $4.2 \mathrm{eV}$ respectively), ${ }^{12}$ and the fact the phenyl rings remain unaffected (Fig. 1), the fragmentation of the molecule likely takes place by the loss of $\mathrm{C}$ and/or $\mathrm{H}$ atoms in the alkyl chain, leading to the formation of $\mathrm{C}=\mathrm{C}$ bonds. These side chain bonds could account for the appearance of the bands at 1630$1660 \mathrm{~cm}^{-1}(\mathrm{C}=\mathrm{C}$, vibration mode $)$ and $1305-1335 \mathrm{~cm}^{-1}$ (=C-bending mode). ${ }^{13}$ For films grown using the ArF laser, the $\mathrm{C}-\mathrm{H}$ related bands have strongly decreased in intensity (3072-3029, 968, 2956-2858 and 1396-1004 $\mathrm{cm}^{-1}$ ) while those related to $\mathrm{C}=\mathrm{C}$ stretching modes in the phenyl rings (1607 and $\left.1495 \mathrm{~cm}^{-1}\right)$ and the cyano group $(\mathrm{C} \equiv \mathrm{N}, 2226$ $\mathrm{cm}^{-1}$ ) remain (Fig. 3). The retention of the cyano group under $193 \mathrm{~nm}$ irradiation contrasts with work on ablation of Polyacrylonitrile ${ }^{5}$, and may be a result of the much lower fluence used here $\left(\sim 30 \mathrm{~mJ} / \mathrm{cm}^{2}\right.$.cf. $>170 \mathrm{~mJ} / \mathrm{cm}^{2}$ in Ref. 5) and differences in primary UV chromophores for Polyacrylonitrile and 5CB. The IR results support findings using HPLC and MALDI-MS that the ArF laser produces severe decomposition of $5 \mathrm{CB}$ and points to a loss of groups from the alkyl side chain. This can be contrasted with the IR spectrum of the $\mathrm{KrF}$ laser deposited film grown at higher fluence (Fig. 3) which shows a close similarity with the thermally evaporated film, suggesting that $5 \mathrm{CB}$ is the predominant composition of the material. Although HPLC analysis showed partial decomposition for the entire $\mathrm{KrF}$ fluence range investigated, the decomposition product is either at a sufficiently low concentration to go undetected in the IR spectrum or has an insufficiently resolved footprint to identify it.

To understand these results we note that $5 \mathrm{CB}$ exhibits a much lower absorption coefficient $(\alpha)$ at $10.6 \mu \mathrm{m}$ than at the deep UV laser wavelengths of 193 and $248 \mathrm{~nm}$. Taking a mean value of $\alpha=47 \mathrm{~cm}^{-1}$ at $10.6 \mu \mathrm{m}^{9}$, the temperature rise per pulse at the focal spot on the liquid pool is estimated to be in the range: $8.4 \mathrm{~K}\left(0.6 \mathrm{~J} / \mathrm{cm}^{2}\right)$ to $42 \mathrm{~K}\left(3 \mathrm{~J} / \mathrm{cm}^{2}\right)$. However, under repetitively pulsed conditions, the slow cooling of the heated zone $(\sim 0.5 \mathrm{~s})$ leads to a large rise ( $\Delta$ $\mathrm{T}_{\mathrm{s}}$ ) in the quasi-steady temperature at the focal spot on the target. For example, at $1.4 \mathrm{~J} / \mathrm{cm}^{2}$ and $8 \mathrm{~Hz}$, a $\Delta \mathrm{T}_{\mathrm{s}} \approx 400 \mathrm{~K}$ is estimated for a surface source with a $0.6 \mathrm{~mm}$ radius spot assuming that convection is negligible. ${ }^{14}$ Under these conditions evaporative flux components arise from the entire surface area of the pool $\left(\sim 38 \mathrm{~mm}^{2}\right)$ as in thermal evaporation, together with a contribution from the focal spot region where the temperature may be sufficiently high to promote some degree of thermal decomposition evidenced in the IR and
MALDI results. At 248 and $193 \mathrm{~nm} 5 \mathrm{CB}$ exhibits very strong absorption by virtue of the $\pi \rightarrow \pi^{*}$ singlet-singlet transitions, with estimated values of $\alpha=6.6 \times 10^{4} \mathrm{~cm}^{-1}$ and $\alpha=2 \times 10^{5} \mathrm{~cm}^{-1}$ respectively. ${ }^{9}$ At $20 \mathrm{~mJ} / \mathrm{cm}^{2}$ this would correspond to a transient surface temperature rise of $1200 \mathrm{~K}$ for the ArF laser. Although this is likely an upper limit on the temperature rise as energy loss to photochemical reaction and heat flow from the shallow absorption zone $\left(\alpha^{-1}=50\right.$ $\mathrm{nm}$ ) are neglected, this magnitude would be more than sufficient to promote removal through an explosive boiling mechanism. In contrast with the $\mathrm{CO}_{2}$ laser, the low fluence required for removal, coupled with rapid cooling of the shallow heated layer $(\sim 25 \mathrm{~ns})$, restricts the extent of long-term temperature rise and thermal decomposition in the liquid pool. These differences in the ejection mechanism are tentatively proposed as explanation for the different film morphologies observed (Fig. 2). The present results show that the $\mathrm{KrF}$ laser wavelength is suitably strongly absorbed to promote an ablative removal of material without excessive fragmentation. This has allowed ultra-thin and uniform films of this LC to be formed, pointing to the potential suitability of PLD for preparing films of other related materials. Work is currently underway to characterise the electro-optic properties of these films and their applicability as liquid crystals.

The authors would like to thank D. Allwood for the MALDI measurements, Dr. H.V. Snelling for helpful discussions and P. Monk and R. Knight for technical assistance. J.G. acknowledges a post-doctoral fellowship from the Spanish Ministry of Educación y Cultura.

${ }^{1}$ H. Korner, A. Shiota, T. J. Bunning, and C. K. Ober, Science 272, 252 (1996).

${ }^{2}$ K. L Saenger, in Pulsed Laser Deposition of Thin Films, ed. by D. B. Chrisey and G. K. Hubler (Wiley, New York 1994).

${ }^{3}$ S. G. Hansen and T. E. Robitalle, Appl. Phys. Lett. 52, 81 (1988).

${ }^{4}$ G. B. Blanchet, Appl. Phys. Lett. 62, 479 (1993).

${ }^{5}$ S. Nishio, T. Chiba, A. Matsuzaki, and H. Sato, J. Appl. Phys. 79, 7198 (1996).

${ }^{6}$ R. Srinavasan and A. P. Ghosh, Chem. Phys. Lett. 143, 546 (1988).

${ }^{7}$ A. J. Salih, S. P. Lau, J. M. Marshall, J. M. Maud, W. R. Bowen, N. Hilal, R. W. Lovitt, and P. M. Williams, Appl. Phys. Lett. 69, 2231 (1996).

${ }^{8}$ T. Fujii, H. Shima, N. Matsumoto, and F. Kannari, Appl. Surf. Sci. 9698, 625 (1996).

${ }^{9}$ I. Ch. Khoo and S. T. Wu in Optics and Nonlinear Optics of Liquid Crystals (World Scientific, Singapore 1993).

${ }^{10}$ A. Itaya, K. Watanabe, T. Inamura, and H. Miyasaka, Thin Solid Films 292, 204 (1997).

${ }^{11}$ C. A. McFarland, J. L. Koenig, and J. L. West, Appl. Spectrosc. 47, 598 (1993).

${ }^{12}$ A. J. Gordon and R. A. Ford in The Chemist's Companion (Wiley, New York 1972), pp. 112-113.

${ }^{13}$ G. Varsányi in Assignements for Vibrational Spectra of Benzene Derivatives, vol. 1 (Adam Hilger Ltd., London 1974).

${ }^{14}$ J. F. Ready in Effects of High Power Laser Radiation (Academic, New York 1971). 